\title{
Changes in Cell Membrane Fatty Acid Composition of Streptococcus thermophilus in Response to Gradually Increasing Heat Temperature
}

\author{
Bonggyu Min ${ }^{1}$, Kkotnim Kim ${ }^{1}$, Vladimir $\mathrm{Li}^{2}$, Seoae $\mathrm{Cho}^{3}$, and Heebal Kim ${ }^{1,2,3 *}$ \\ ${ }^{1}$ Department of Agricultural Biotechnology and Research Institute of Agriculture and Life Sciences, Seoul National \\ University, Seoul 08826, Republic of Korea \\ ${ }^{2}$ Interdisciplinary Program in Bioinformatics, Seoul National University, Seoul 08826, Republic of Korea \\ ${ }^{3}$ C\&K genomics Inc., C-1008, H businesspark, Seoul 08826, Republic of Korea
}

In this study, a method of heat adaptation was implemented in an attempt to increase the upper thermal threshold of two Streptococcus thermophilus found in South Korea and identified the alterations in membrane fatty acid composition to adaptive response to heat. In order to develop heat tolerant lactic acid bacteria, heat treatment was continuously applied to bacteria by increasing temperature from $60^{\circ} \mathrm{C}$ until the point that no surviving cell was detected. Our results indicated significant increase in heat tolerance of heat-adapted strains compared to the wild type (WT) strains. In particular, the survival ratio of basically low heat-tolerant strain increased even more. In addition, the strains with improved heat tolerance acquired cross protection, which improved their survival ratio in acid, bile salts and osmotic conditions. A relation between heat tolerance and membrane fatty acid composition was identified. As a result of heat adaptation, the ratio of unsaturated to saturated fatty acids (UFA/SFA) and C18:1 relative concentration were decreased. C6:0 in only heatadapted strains and C22:0 in only the naturally high heat tolerant strain were detected. These results support the hypothesis, that the consequent increase of SFA ratio is a cellular response to environmental stresses such as high temperatures, and it is able to protect the cells from acid, bile salts and osmotic conditions via cross protection. This study demonstrated that the increase in heat tolerance can be utilized as a mean to improve bacterial tolerance against various environmental stresses.

Keywords: Probiotics, Streptococcus thermophilus, heat Adaptation, cross protection, fatty acid composition, membrane fluidity

Received: January 2, 2020 Accepted: February 28, 2020

\section{First published online:} March 02, 2020

* Corresponding author Phone: +82-2-880-4803 Fax: +82-2-883-8812 E-mail: heebal@snu.ac.kr

Supplementary data for this paper are available on-line only at http://jmb.or.kr.

pISSN 1017-7825 elSSN 1738-8872

Copyright(C) 2020 by The Korean Society for Microbiology and Biotechnology

\section{Introduction}

Probiotics are living microorganisms whose inclusion in the diet intends to provide health benefits of the host by improving intestinal environment [1]. Lactic acid bacteria (LAB) belong to a class of probiotic bacteria that has been extensively used in food industries and especially dairy product industry. Streptococcus thermophilus belongs to LAB class bacteria, and it has been extensively used in the food industry [2]. As suggested by its name, S. thermophilus is thermophilic lactic acid bacteria. They have the ability to withstand relatively high temperatures. During past decades, this species has been commonly used for the production of fermented dairy foods because it both enhances the flavor of dairy products, and accelerates the ratio of product acidification [3].

During industrial processes, bacteria may experience various environmental stresses such as low $\mathrm{pH}$ and osmotic pressure. Heat stress has been one of the most widely studied topics of LAB [4]. Elevated temperatures $\left(>60^{\circ} \mathrm{C}\right)$ are required for certain manufacturing processes such as pasteurization, which can negatively affect bacterial growth and even lead to cell death [5]. This led to the increased interests in expanding LAB abilities to survive under these heat stress conditions, several studies on their heat tolerance were reported [6,7].

Stress adaptation among LAB varies with respect to bacterial species and stress conditions, but the critical response to the adaptation of LABs at various stresses involves major changes in membrane fatty acid composition [8]. Several studies have shown that a link between the membrane fatty acid composition and the bacterial heat tolerance has been found that the adaptation of bacteria in the stress conditions induced change of cell membrane fatty acid composition $[9,10]$. The ratio between unsaturated and saturated fatty acids (UFA/SFA) is inversely correlated with the growth temperature [11]. Zhang and Rock stated that bacterial cells can control the 
biosynthesis of new fatty acids or can modify the structure of existing ones, and this allows bacteria to alter cell membrane fluidity and rapidly adapt to the changed environmental conditions [12].

The aim of this study was to identify the adaptive response to heat and the modifications in membrane fatty acid composition of $S$. thermophilus after its exposure to high temperature. Previous studies have been carried out about resistance to temperature related stresses of $S$. thermophilus $[13,14]$. However, to our knowledge, there is no study available for $S$. thermophilus that the responses of cells after exposed heat stress over 60 degrees or a relation of adaptation of this stressful condition and the changes of membrane fatty acid composition. In our study, we applied a newly designed adaptive evolutionary method to induce heat adaptation of $S$. thermophilus strains. The heat tolerance of two $S$. thermophilus, BIOPOP-1 and BIOPOP-2, isolated from fermented dairy foods in South Korea was improved as adaptation in gradually increasing heat temperature condition. In addition, the difference in improve stress tolerance of these two strains that inherently high heat tolerance and those having low heat tolerance when cultured at $50^{\circ} \mathrm{C}$ was identified. This study provided not only an approach to improve bacterial tolerance response in high temperature but also an insight into the stress cross protection [15]. The alteration in cell membrane fatty acid composition of $S$. thermophilus strains achieved by adaptation through only heat-shock response in high temperature without additional stress. It was hypothesized that the heat-adapted bacteria not only tolerate high temperature, but also can withstand various stress conditions. Through this study, we proved that one cause of these reasons is alteration of cell membrane fatty acid composition. This method can be applied in wide range of industries.

\section{Materials and Methods \\ Isolation and Selection of Heat Tolerant Bacterial Strains}

Several strains were isolated from fermented dairy foods in South Korea and only 8 catalase negative and Grampositive isolates were selected [16]. They were cultured in sterile deMan Rogosa Sharpe medium (MRS, Difco, Becton Dickinson Co., USA) and incubated at $37^{\circ} \mathrm{C}$ for $24 \mathrm{~h}$. To screen for naturally heat tolerant strains, cells were incubated at $50^{\circ} \mathrm{C}$ for $24 \mathrm{~h}$ and two surviving isolates were selected. The cells were labeled as BIOPOP-1 and BIOPOP-2 and stored as stock samples in $40 \%$ glycerol at $-80^{\circ} \mathrm{C}$ [17].

\section{Identification of the Isolates with $16 \mathrm{~S}$ rRNA Gene Sequencing}

BIOPOP-1 and BIOPOP-2 strains were identified using $16 \mathrm{~S}$ ribosomal RNA (rRNA) gene sequencing method. Genomic DNA was extracted according to the instruction provided by the manufacturer of DNA extraction kit (QIAGEN, USA) [16]. The 16S rRNA gene was amplified using the universal bacterial primer sets: 27F 5' (AGA GTT TGA TCM TGG CTC AG) 3' and 1492R 5' (TAC GGY TAC CTT GTT ACG ACT T) 3' [18]. Amplified PCR products were sent for sequencing (Macrogen, Korea) and then results were used for assigning taxonomy using EZ-Biocloud server [19]. The phylogenetic trees were built based on the 16S rRNA gene sequences using the neighbor-joining methods by the MEGA-X software [20]. The $16 \mathrm{~S}$ rRNA gene sequences of 12 Streptococci strains and one Lactococcus lactis for using as out group were downloaded from the National Center for Biotechnology Information (NCBI) database.

\section{Heat Adaptation Procedure}

Two strains of $S$. thermophilus, BIOPOP-1 and BIOPOP-2, were the starting material for the experiment [4]. Cultures from the stocks were streaked on the MRS agar plate and incubated at $37^{\circ} \mathrm{C}$ for $48 \mathrm{~h}$. Each colony was isolated and transferred to $10 \mathrm{ml}$ MRS and incubated at $37^{\circ} \mathrm{C}$ for $24 \mathrm{~h}$. After incubation, $10 \mu \mathrm{l}$ of each sample was transferred to $1.5 \mathrm{ml}$ micro tube with $990 \mu \mathrm{l}$ MRS broth pre-heated at test temperature and heat treatment was performed in a dry bath for $1 \mathrm{~min}$. Samples were cooled down for $5 \mathrm{~min}$ at room temperature, and incubated at $37^{\circ} \mathrm{C}$ for $24 \mathrm{~h}$. This procedure was repeated two more times and then the temperature was increased by $3^{\circ} \mathrm{C}$. Repeated incremental heat treatment was performed starting from $60^{\circ} \mathrm{C}$ until the point all bacteria were not detected. Heat-treated strains, which underwent the procedure for three days, were collected after incubation to measure changes in their heat tolerance levels at each temperature point. [21]. Collected samples then were stored at $-80^{\circ} \mathrm{C}$ in $40 \%$ glycerol as stock solutions and the final surviving strains were designated as heat-adapted strains.

\section{Identification of Heat Tolerance Enhancement}

The stocks of each temperature sample collected in the above step were thawed at room temperature and streaked on MRS agar plates. They were incubated at $37^{\circ} \mathrm{C}$ for $48 \mathrm{~h}$ and then each single colony was individually transferred to tubes with $10 \mathrm{ml} \mathrm{MRS} \mathrm{broth} \mathrm{and} \mathrm{incubated} \mathrm{at} 37^{\circ} \mathrm{C}$ for $24 \mathrm{~h} .10 \mu \mathrm{l}$ of each sample was transferred to $1.5 \mathrm{ml}$ micro tube with $990 \mu \mathrm{l}$ MRS broth pre-heated at $72^{\circ} \mathrm{C}$ and heated for 1 min using a dry bath. After the heat treatment, they were cooled down for about $5 \mathrm{~min}$ at room temperature. Samples were serially diluted with $0.85 \%$ saline, then spread on MRS agar plates and incubated at $37^{\circ} \mathrm{C}$ for $48 \mathrm{~h}$. The survival ratio was calculated by dividing Colony-Forming Units (CFUs) of the stress treated cultures by the CFU of non-treated (control) cultures [22].

\section{Viability Comparison between WT and Heat-Adapted Strains}

Heat treatment with variable temperatures at the set time. The stocks of WT and heat-adapted strains were thawed at room temperature and streaked on agar plates. After incubated the plates at $37^{\circ} \mathrm{C}$ for $48 \mathrm{~h}$, isolated single colonies of each plate were transferred into test tubes with $10 \mathrm{ml}$ of MRS and incubated at $37^{\circ} \mathrm{C}$ for $24 \mathrm{~h}$. Heat treatment was performed in dry bath with base temperature set to $60^{\circ} \mathrm{C}$ for both WT and heat-adapted strains, temperature increment was $3^{\circ} \mathrm{C}$ until final survival temperature was reached for each sample. Cells were 
inoculated in MRS broth $(10 \mu$ cells, $990 \mu \mathrm{l}$ media) at each temperature point from 60 to final survived temperature of each strains and heated for $1 \mathrm{~min}$. They were then serially diluted with $0.85 \%$ saline and transferred on MRS agar plate and incubated at $37^{\circ} \mathrm{C}$ for $48 \mathrm{~h}$.

Prolonged heat treatment at constant temperature. Subcultures of WT and heat-adapted strains were prepared using samples from previous part. They inoculated $100 \mathrm{ul}$ into $10 \mathrm{ml}$ pre-heated MRS broth and heated in a water bath at $60^{\circ} \mathrm{C}$ from 0 to $50 \mathrm{~min} 100 \mu \mathrm{l}$ of the cells were transferred to tubes with $10 \mathrm{ml}$ pre-heated MRS broth [23]. The survival ratio was checked every $10 \mathrm{~min}$. After heat treatment, they were left to cool down for $5 \mathrm{~min}$ at room temperature. Cells then were serially diluted with $0.85 \%$ saline and spread on MRS agar plates and incubated at $37^{\circ} \mathrm{C}$ for $48 \mathrm{~h}$.

The $\mathrm{D}$-value (decimal reduction time) was determined given by the equation:

$$
\mathrm{t}=\mathrm{D} \times\left(\log \mathrm{N}_{0}-\log \mathrm{N}_{\mathrm{f}}\right) \text {, }
$$

where t: time $(\min ), D$ : $D$-value at heat conditions, $\mathrm{N}_{0}$ : initial concentration of microorganisms, $\mathrm{N}_{\mathrm{f}}$ : final concentration of microorganisms [24]. D-value of each strain was calculated as the negative inverses of the regression line slopes obtained by plotting the log number of survivors against time [25].

\section{Assessment of Tolerance Enhancement in Other Stresses after Heat Adaptation}

The stocks of WT and heat-adapted strains were thawed at room temperature and streaked on agar plates. After incubated the plates at $37^{\circ} \mathrm{C}$ for $48 \mathrm{~h}$, isolated single colonies of each plate were transferred into test tubes with $10 \mathrm{ml}$ of MRS and incubated at $37^{\circ} \mathrm{C}$ for $24 \mathrm{~h}$. Cells were then harvested by centrifugation $(4,000 \mathrm{rpm}, 10 \mathrm{~min}$, and $4^{\circ} \mathrm{C}$ ). They were washed twice with phosphate-buffered saline (PBS) with $\mathrm{pH}$ 7.0. To measure response against acid, cell pellets were re-suspended with MRS broth adjusted to 2, 3, and 7 (control) [26]. Cell suspensions were incubated at $37^{\circ} \mathrm{C}$ for $2 \mathrm{~h}$. To evaluate their viability, they were serially diluted and spread on MRS agar plates, then incubated at $37^{\circ} \mathrm{C}$ for $48 \mathrm{~h}$.

Bile salt tolerance of each strain was examined. Cells were harvested following the same protocol as in the acid tolerance experiment and re-suspended by MRS containing $0.5 \%$ and $1 \%$ bile salts (cholic acid sodium salt $50 \%$ and deoxycholic acid sodium salt 50\%, Sigma Aldrich, 48305) [26]. Cell suspensions were incubated at $37^{\circ} \mathrm{C}$ for $3 \mathrm{~h}$. Then serially diluted, spread on MRS agar plates and incubated at $37^{\circ} \mathrm{C}$ for $48 \mathrm{~h}$.

To assess osmotic tolerance, bacteria were harvested following the same protocol as in the acid tolerance experiment. Cell pellets were then re-suspended by MRS containing $20 \% \mathrm{NaCl}$ (Sodium chloride, $99.5 \%$ ). The cell suspensions were incubated at $37^{\circ} \mathrm{C}$ for $2 \mathrm{~h}$ and $24 \mathrm{~h}$, serially diluted, spread on MRS agar plates. Then, plates incubated at $37^{\circ} \mathrm{C}$ for $48 \mathrm{~h}$. The survival ratio was calculated by dividing CFUs of the stress treated cultures by the CFU of non-treated (control) cultures [22].

\section{Analysis of Fatty Acid Component of Bacterial Membrane}

Fatty acids analysis was performed according to the method outlined by Garces and Mancha [27]. The stocks of WT and heat-adapted strains were thawed at room temperature and streaked on agar plates. Plates were then incubated at $37^{\circ} \mathrm{C}$ for $48 \mathrm{~h}$, single colonies from each plate were transferred into test tubes with $10 \mathrm{ml}$ of MRS and incubated at $37^{\circ} \mathrm{C}$ for $24 \mathrm{~h}$. Cells were then harvested by centrifugation and washed twice with distilled water. Pellets were transferred to tubes with Teflon-lined caps and pentadecenoic acid (15:0) was used as an internal standard. Samples were mixed with methylation mixture containing methanol, benzene, DMP (2, 2-Dimethoxypropane), sulfuric acid $\left(\mathrm{H}_{2} \mathrm{SO}_{4}\right)$ and heptane. For lipid extraction tubes were placed in a water bath at $80^{\circ} \mathrm{C}$ for $2 \mathrm{~h}$. They were then cooled down at room temperature. The samples were shaken, and The samples were shaken, and left to settle, after which the content formed two layers. The top layer containing Fatty Acid Methyl Esters (FAMEs) was extracted and analyzed using Agilent 7890A gas chromatography (Agilent, USA) equipped with a flame ionization detector (FID) and a DB-23 column $(60 \mathrm{~mm} \times 0.25 \mathrm{~mm} \times 0.25 \mathrm{um})$ (Agilent Technologies, Inc., Wilmington, DE). GC settings: injector temperature $250^{\circ} \mathrm{C}$, split ratio $10: 1$, carrier flow $1.2 \mathrm{ml} / \mathrm{min}$, detector temperature $280^{\circ} \mathrm{C}$, air flow in detector $350 \mathrm{ml} / \mathrm{min}$, hydrogen flow $35 \mathrm{ml} / \mathrm{min}$. The results were shown as relative percentages of each fatty acid and the ratios of saturated fatty acids (SFAs) and unsaturated fatty acids (UFAs) were calculated [23].

\section{Statistical Analysis}

All experiments were conducted three times. The Colony-Forming Units (CFUs) were counted and the viability was calculated by dividing the CFUs of the test cultures by the CFUs of non-treated (control) [22]. The results were indicated as mean $\pm \mathrm{SD}$ (standard deviation) [26]. Independent $\mathrm{t}$-tests for statistical analyses were performed using R software [28] and $P$-value was considered statistically significant $(p<0.05)$ [16].

\section{Results}

\section{Screening and Phylogenetic Analysis of the Strains}

Strains were isolated from fermented dairy foods and appeared as gram-positive and catalase-negative bacteria. Two globular-shaped strains BIOPOP- 1 and BIOPOP-2 were selected after incubation at $50^{\circ} \mathrm{C}$ for $24 \mathrm{~h}$. Strain BIOPOP-1 demonstrated adequate survival and proliferation ratios $(97.59 \pm 1.40 \%)$, while strain BIOPOP-2 showed positive survival ratio, comparatively low proliferation ratio $(7.06 \pm 0.67 \%)$.

Phylogenetic tree based on the 16S rRNA gene sequences was built (Fig. 1). According to it, strains BIOPOP-1 and BIOPOP-2 were identified as Streptococcus thermophilus. The $16 \mathrm{~S}$ rRNA gene of strain BIOPOP-1 had 99.8\% match with S. thermophilus type strain ATCC 19258 and strain BIOPOP-2's 16S rRNA gene had 99.25\% match 


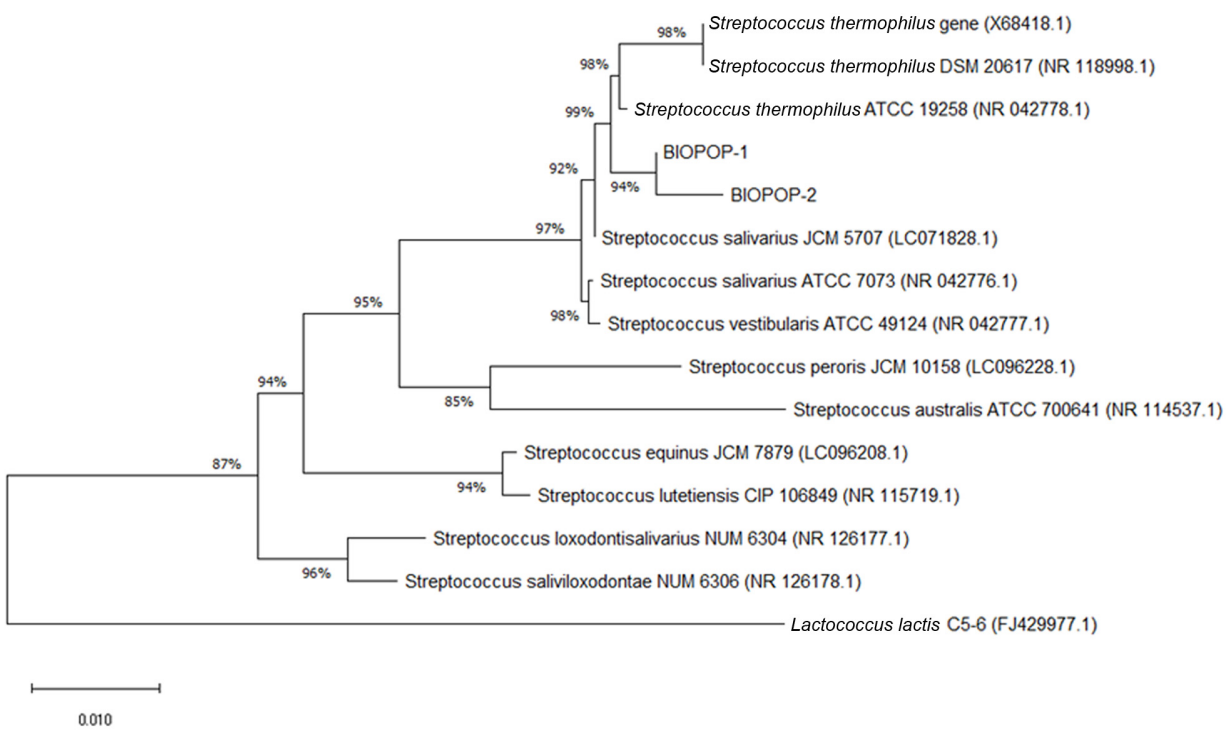

Fig. 1. Phylogenetic relationship of the isolates with related taxa based on 16S rRNA sequences. Neighbourjoining tree showing the phylogenetic relationships of strain BIOPOP-1, strain BIOPOP-2 and related type strains. 16S rRNA gene sequence of Lactococcus lactis was used as out group.

with S. thermophilus type strain ATCC 19258 (Table S1) [29]. Although strains BIOPOP-1 and BIOPOP-2 were of the same species, they showed completely different levels of natural heat tolerance.

\section{Increasing Bacterial Heat Tolerance Threshold by Heat Adaptation}

The cells were subjected to heat adaptation procedure by gradually elevating the base $\left(60^{\circ} \mathrm{C}\right)$ temperature [30]. The process of this experiment is outlined in Fig. 2. BIOPOP-1 strain was able to withstand temperatures up to

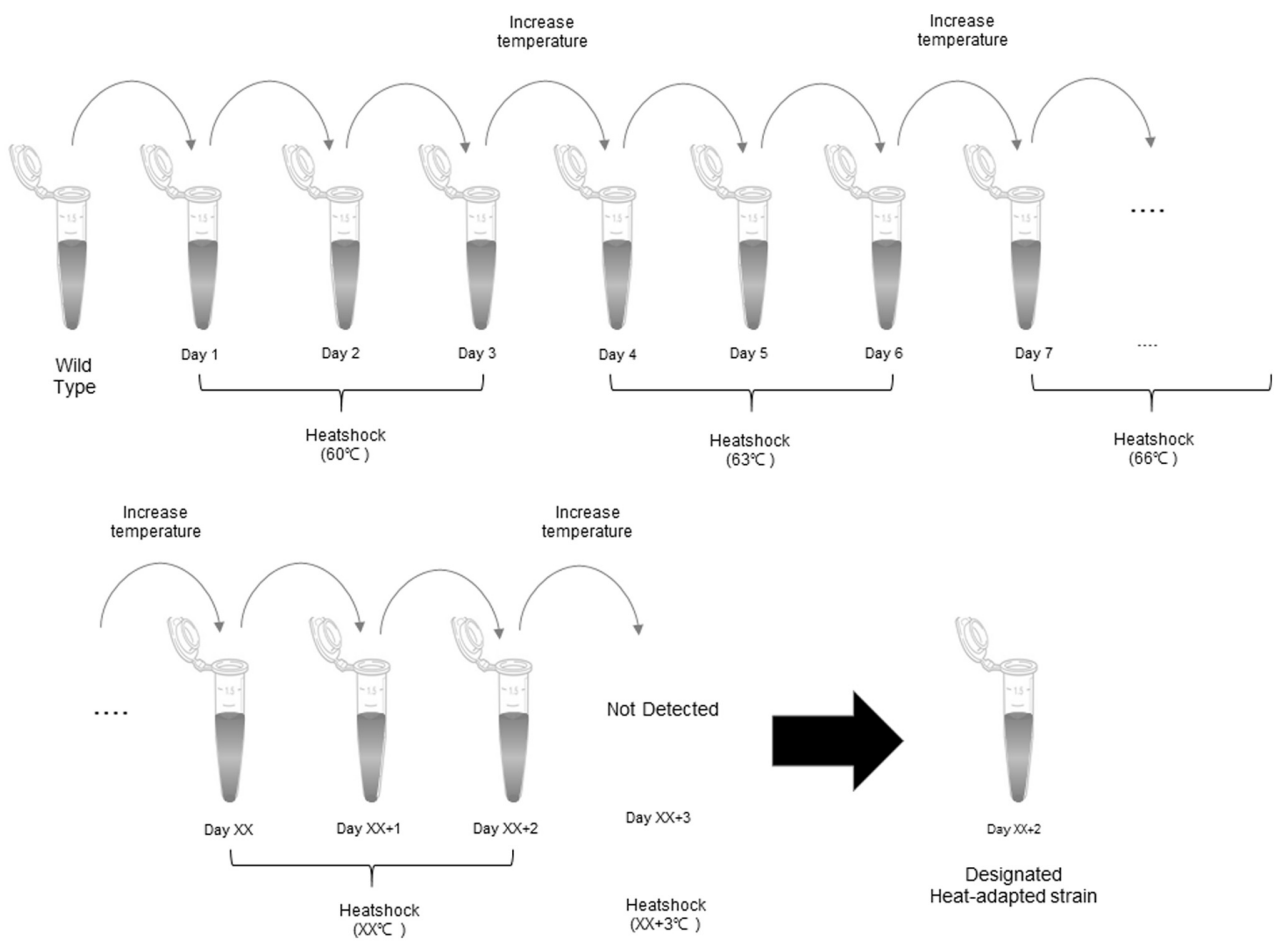

Fig. 2. Procedure for heat adaptation experiment. Temperatures was gradually increased from $60^{\circ} \mathrm{C}$ until strains were not detected. $10 \mu \mathrm{l}$ of each sample was transferred to $1.5 \mathrm{ml}$ micro tube with $990 \mu \mathrm{l}$ MRS broth pre-heated at test temperature. Heat shock time was $1 \mathrm{~min}$ and then incubated at $37^{\circ} \mathrm{C}$ for $24 \mathrm{~h}$. This procedure was repeated three times and increased temperature $\left(3^{\circ} \mathrm{C}\right)$. The final surviving bacteria were designated as heat-adapted strains. 
A

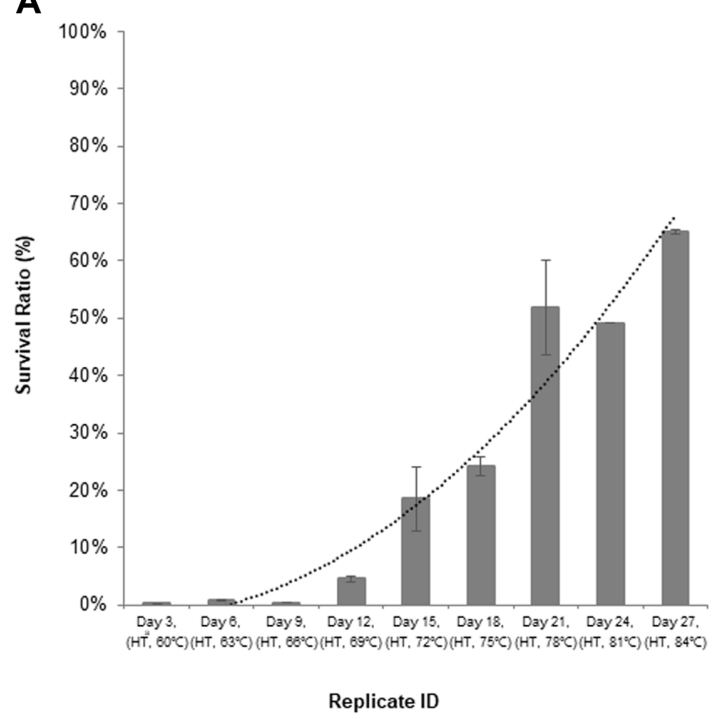

B

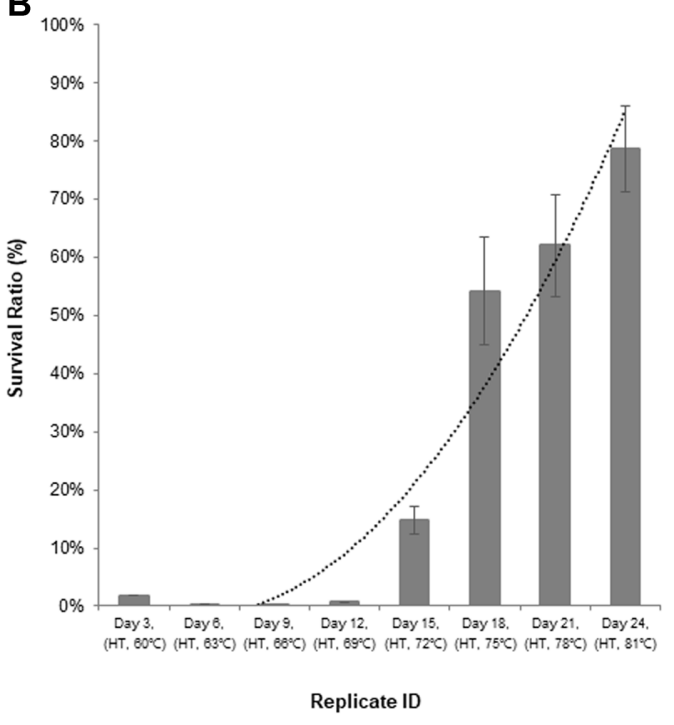

a HT : The heating temperature used for three days

Fig. 3. Enhancement of heat tolerance threshold of $S$. thermophilus. (A) S. thermophilus BIOPOP-1, (B) S. thermophilus BIOPOP-2. X axis represents strains that were taken from the last step (day 3) of each heat treatment temperature in heat-adaptation process. HT means the heating temperature used for three days and $Y$ axis presents the percentage of strain's survival ratio (\%) that was calculated by dividing the CFUs of the heat-treated cultures by the CFUs of non-treated (control). The error bars represent the calculated standard deviation of the measurements of three biological replicates.

$84^{\circ} \mathrm{C}$, while BIOPOP-2 strain only survived up until $81^{\circ} \mathrm{C}$ was reached. The surviving bacteria were designated as heat-adapted strains (BIOPOP-1: $84^{\circ} \mathrm{C}$, BIOPOP-2: $81^{\circ} \mathrm{C}$ ).

To assess enhanced heat tolerance of the strains, we thawed the stocks that were made the third day of each temperature during heat-adaptation procedure. They were cultured and subjected to the heat shock at $72^{\circ} \mathrm{C}$ for $1 \mathrm{~min}$. Heat shock temperature, $72^{\circ} \mathrm{C}$, is a midpoint within acceptable temperature range for the both strains, and is a deciding criterion for using in the test. As a result, BIOPOP- 1 strain demonstrated that $60^{\circ} \mathrm{C}$ strain was the lowest viability and the low viability was almost maintained up to $66^{\circ} \mathrm{C}$ strain. However, the viability was gradually increased from $69^{\circ} \mathrm{C}$ strain and $84^{\circ} \mathrm{C}$ (heat-adapted) strain was the highest (Fig. 3A). In case of BIOPOP-2 strain, cell viabilities were low up to $69^{\circ} \mathrm{C}$ strains, but it drastically increased from $72^{\circ} \mathrm{C}$ strain. The highest viability data were recorded $81^{\circ} \mathrm{C}$ (heat-adapted) strain (Fig. 3B).

A

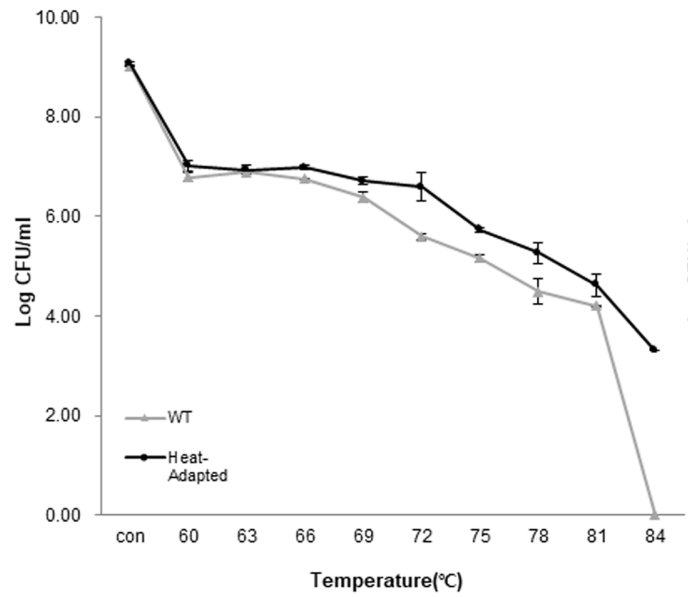

B

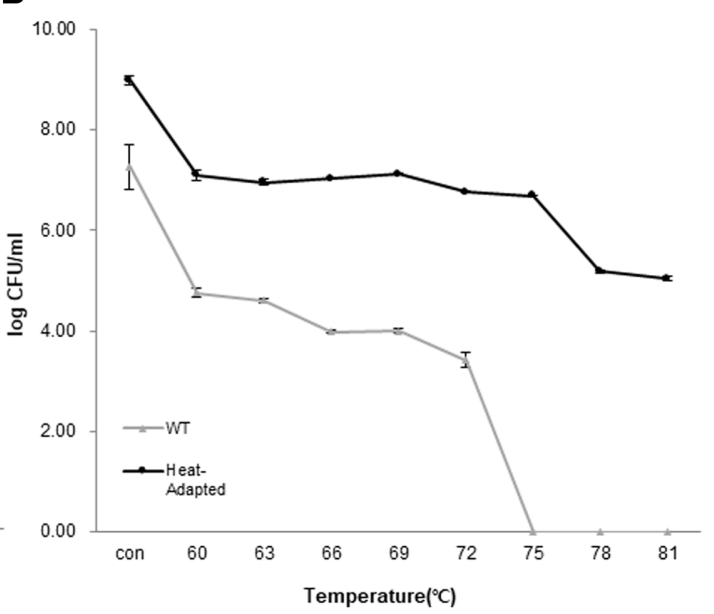

Fig. 4. The results of heat treatment with variable temperatures at the set time. (A) S. thermophilus BIOPOP-1, (B) S. thermophilus BIOPOP-2. Heat shock time was set at $1 \mathrm{~min}$ and heated from $60^{\circ} \mathrm{C}$ to strains final temperature. The survival ratio of the bacteria was determined by counting the CFUs on MRS agar plate and expressed in log values. The error bars represent the calculated standard deviation of the measurements of three biological replicates. 
Viability Comparison between WT and Heat-Adapted Strains

Heat shock with variable temperatures at set time. Starting from basal $60^{\circ} \mathrm{C}$, cells were subjected to heat treatment with gradual temperature increment of $3^{\circ} \mathrm{C}$ every $1 \mathrm{~min}$ until final survival temperature was reached; $84^{\circ} \mathrm{C}$ for BIOPOP- 1 and $81^{\circ} \mathrm{C}$ for BIOPOP- 2 correspondingly. BIOPOP- 1 strain showed no significant difference in cell viability between WT and heat-adapted strains. Nevertheless, the viability of heat-adapted strain was slightly higher than the WT sample. Upon reaching $84^{\circ} \mathrm{C}$, no viable WT cells were observed, while most of the heat-adapted strain cells remained alive (Fig. 4A). In case of BIOPOP-2 strain, WT cells were not detected from temperature reached $75^{\circ} \mathrm{C}$, while the heat-adapted strain were detected until reaching $81^{\circ} \mathrm{C}$ (Fig. $\left.4 \mathrm{~B}\right)$. Overall, the results demonstrated positive increment of heat tolerance in heat-adapted strains compared to WT.

Prolonged heat treatment at constant temperature. Cells were heated at $60^{\circ} \mathrm{C}$ for 0 to $50 \mathrm{~min}$ to assess their heat tolerance level [23]. The cell viability of heat-adapted strain was much higher than that of WT cells for the most of the time. In case of strain BIOPOP-1, the results of WT strain and heat-adapted strain were similar until reaching $10 \mathrm{~min}$ time period. However, the number of viable cells started to gradually different after $20 \mathrm{~min}$, and no growth was detected at $50 \mathrm{~min}$ time limit, but heat-adapted strain was still within the adequate values (Fig. $5 \mathrm{~A}$ ). Likewise, the viability of BIOPOP-2 showed that no growth of WT cells was detected after 40 min time period, while heat-adapted strain remained alive until 50 min time limit (Fig. 5B).

Microorganisms defined their heat tolerance by D-value (decimal reduction time) which is exposure time required to causes one $\log _{10}$ or $90 \%$ reduction of the initial population under specified temperature [18]. Comparing WT and heat-adapted strains, heat-adapted strain of BIOPOP-1 was higher (D-value of $2.0 \mathrm{~min}$ ) than WT strain (D-value of $1.4 \mathrm{~min}$ ) and BIOPOP-2 heat-adapted strain was also higher than WT strain that D-value of WT strain was $1.1 \mathrm{~min}$ and heat-adapted strain was $2.7 \mathrm{~min}$ [25]. The result proved that heat-adapted strains enhanced their heat tolerance through heat adaptation procedure and the overall results of this method positively correlate with the results of the upper method, demonstrating stable positive increment towards heat survivability of heat-adapted strains.

Heat Adaptation Induced Cross Protection Enhancement against Various Environmental Stresses

The higher the heat tolerance, the stronger tolerance to other stresses by cross protection [31]. In order to confirm this, the strains with increased heat tolerance through heat-adapted experiment were exposed to various stress environments such as acid, bile salt and salinity. Table 1 summarizes the results of cross protection in these stress conditions.

Acid tolerance. Acid tolerance is one of the vital abilities of LABs necessary to survive in acidic environment of the stomach after being ingested [32]. The average $\mathrm{pH}$ of the stomach is $2 \sim 3$ and it takes about $2 \sim 3 \mathrm{~h}$ for food to move through the digestive tract [33]. WT and heat-adapted strains were exposed deMan Rogosa sharpe (MRS) medium where the $\mathrm{pH}$ was adjusted to 2 and 3 . When exposed to $\mathrm{pH} 3$ for $2 \mathrm{~h}$, all strains showed that survival ratios were similarly high. The WT of BIOPOP- 1 strain was $78.18 \%$ and WT of BIOPOP-2 was $69.81 \%$, while that of BIOPOP-1's heat-adapted strain was $83.13 \%$ and strain BIOPOP- 2 was $91.76 \%$. However, exposing bacteria to $\mathrm{pH}$ 2 for $2 \mathrm{~h}$ showed significant change in survival ratios that all strains were dramatically decreased than exposing bacteria to $\mathrm{pH}$ 3. The survival ratio was that WT strain of both BIOPOP- 1 and BIOPOP- 2 was $0.002 \%$, while that of BIOPOP-1 heat-adapted strain was $0.48 \%$ and BIOPOP- 2 was $0.53 \%$.

Bile salts tolerance. The ability of lactic acid bacteria to survive under bile salts environments is also important for probiotics [26]. Both WT and heat-adapted strains were exposed to $0.5 \%$ bile salts for consequent $3 \mathrm{~h}$. The

A

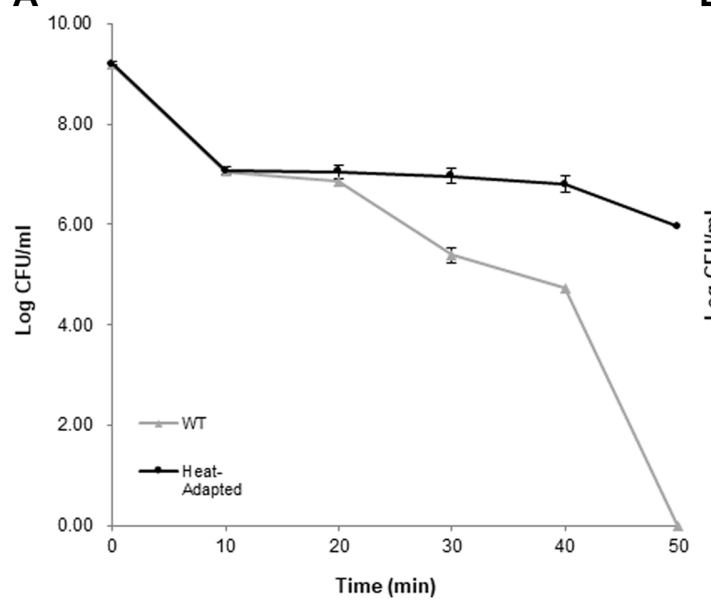

B

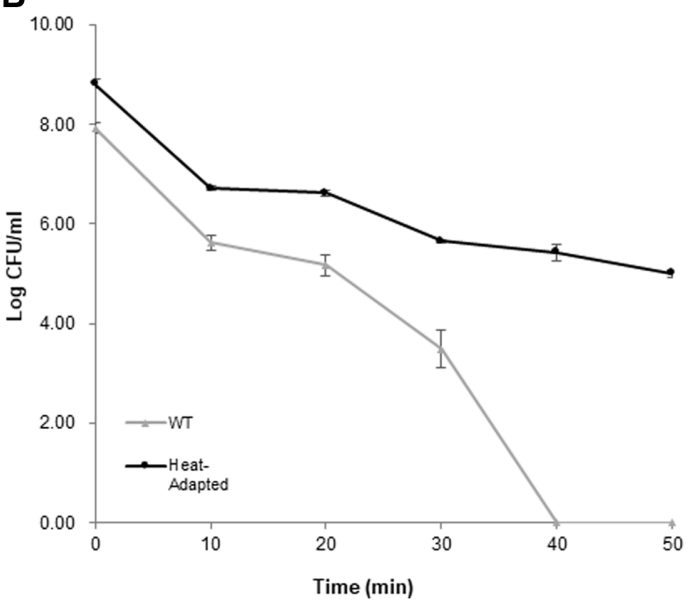

Fig. 5. The results of prolonged heat treatment at constant temperature. (A) S. thermophilus BIOPOP-1, (B) S. thermophilus BIOPOP-2. The heat temperature was set to $60^{\circ} \mathrm{C}$ and the heat treatment proceeded until $50 \mathrm{~min}$. Survival ratio was checked every $10 \mathrm{~min}$. The survival ratio of the bacteria was determined by counting the CFUs on MRS agar plate and expressed in log values. The error bars represent the calculated standard deviation of the measurements of three biological replicates. 
Table 1. The results of cross protection against acid, bile salt and salinity condition.

\begin{tabular}{|c|c|c|c|c|c|c|}
\hline & & & \multicolumn{2}{|c|}{ BIOPOP-1 } & \multicolumn{2}{|c|}{ BIOPOP-2 } \\
\hline & & & WT & Heat-Adapted & WT & Heat-Adapted \\
\hline \multirow[t]{5}{*}{ Acid } & Con. $^{a}$ & $\log \mathrm{CFU} / \mathrm{ml}$ & $9.21 \pm 0.06$ & $9.21 \pm 0.07$ & $9.12 \pm 0.1$ & $9.23 \pm 0.03$ \\
\hline & $\mathrm{pH} 2$ & $\log \mathrm{CFU} / \mathrm{ml}$ & $4.54 \pm 0.04$ & $5.80 \pm 0.01$ & $4.43 \pm 0.07$ & $6.95 \pm 0.01$ \\
\hline & & $\mathrm{SR}^{\mathrm{b}}(\%)$ & $0.002 \%$ & $0.48 \%$ & $0.002 \%$ & $0.53 \%$ \\
\hline & $\mathrm{pH} 3$ & $\log \mathrm{CFU} / \mathrm{ml}$ & $9.10 \pm 0.05$ & $9.14 \pm 0.01$ & $8.97 \pm 0.08$ & $9.19 \pm 0.003$ \\
\hline & & $\mathrm{SR}^{\mathrm{b}}(\%)$ & $78.18 \%$ & $83.13 \%$ & $69.81 \%$ & $91.76 \%$ \\
\hline \multirow[t]{5}{*}{ Bile Salt } & Con. $^{a}$ & $\log \mathrm{CFU} / \mathrm{ml}$ & $8.32 \pm 0.03$ & $8.89 \pm 0.08$ & $7.47 \pm 0.1$ & $9.18 \pm 0.03$ \\
\hline & $0.5 \%$ & $\log \mathrm{CFU} / \mathrm{ml}$ & $6.57 \pm 0.02$ & $8.76 \pm 0.03$ & $4.78 \pm 0.06$ & $9.18 \pm 0.01$ \\
\hline & & $\mathrm{SR}^{\mathrm{b}}(\%)$ & $1.75 \%$ & $71.82 \%$ & $0.19 \%$ & $98.91 \%$ \\
\hline & $1.0 \%$ & $\log \mathrm{CFU} / \mathrm{ml}$ & $\mathrm{ND}^{\mathrm{c}}$ & $4.36 \pm 0.06$ & $\mathrm{ND}^{\mathrm{c}}$ & $6.62 \pm 0.08$ \\
\hline & & $\mathrm{SR}^{\mathrm{b}}(\%)$ & - & $0.29 \%$ & - & $0.28 \%$ \\
\hline \multirow[t]{5}{*}{ Salinity } & Con. $^{a}$ & $\log \mathrm{CFU} / \mathrm{ml}$ & $9.20 \pm 0.02$ & $8.96 \pm 0.08$ & $8.21 \pm 0.09$ & $8.66 \pm 0.04$ \\
\hline & $2 \mathrm{~h}$ & $\log \mathrm{CFU} / \mathrm{ml}$ & $8.24 \pm 0.01$ & $8.65 \pm 0.004$ & $6.95 \pm 0.03$ & $8.13 \pm 0.01$ \\
\hline & & $\mathrm{SR}^{\mathrm{b}}(\%)$ & $10.88 \%$ & $47.62 \%$ & $5.35 \%$ & $29.34 \%$ \\
\hline & $24 \mathrm{~h}$ & $\log \mathrm{CFU} / \mathrm{ml}$ & $6.67 \pm 0.01$ & $7.53 \pm 0.05$ & $5.42 \pm 0.03$ & $7.56 \pm 0.01$ \\
\hline & & $\mathrm{SR}^{\mathrm{b}}(\%)$ & $0.29 \%$ & $6.63 \%$ & $0.16 \%$ & $7.88 \%$ \\
\hline
\end{tabular}

The viabilities are expressed as mean \pm standard deviation of the measurements of three biological replicates.

${ }^{a}$ Con : Control, cells under no stress.

bR : Survival Ratio (\%)

${ }^{\mathrm{N} D}$ : Not Detected

survival ratio of BIOPOP-1 (WT) was $1.75 \%$ and BIOPOP-2 (WT) was $0.19 \%$, while that of BIOPOP-1 (heatadapted) was $71.82 \%$ and BIOPOP-2 (heat-adapted) was $98.91 \%$. Cells were then exposed to $1.0 \%$ bile salts for $3 \mathrm{~h}$, and while survival ratio of BIOPOP-1 (heat-adapted) was $0.29 \%$ and BIOPOP-2 (heat-adapted) was $0.28 \%$; WT cells were not detected at all. Thus, the results revealed the heat-adapted strains also acquired improved bile tolerance induced by heat.

Osmotic tolerance. One of the methods usually used for preserving foods is to increase osmotic pressure by supplementing salts such as $\mathrm{NaCl}$ or $\mathrm{KCl}$ [34]. To evaluate osmotic tolerance, WT and heat-adapted strains were first exposed to MRS containing $10 \% \mathrm{NaCl}$ for $24 \mathrm{~h}$, and both strains demonstrated $100 \%$ survival ratio. When exposed to MRS containing $20 \% \mathrm{NaCl}$ for $2 \mathrm{~h}$, the survival ratio of BIOPOP-1 (WT) dropped to $10.88 \%$ and BIOPOP-2 (WT) to 5.35\%, while that of BIOPOP-1 (heat-adapted) was $47.62 \%$ and BIOPOP-2 (heat-adapted) was $29.34 \%$. Lastly, the bacteria were exposed to $20 \% \mathrm{NaCl}$ for $24 \mathrm{~h}$, and demonstrated the following survival ratios: BIOPOP-1 (WT): 0.29\%, BIOPOP-2 (WT): 0.16\%, and BIOPOP-1 (heat-adapted): $6.63 \%$, BIOPOP-2 (heat-adapted): $7.88 \%$. Again, these data positively correlate with the previous stress experiments

Influence of Heat Adaptation on Membrane Fatty Acid Composition of S. thermophilus

A chromatographic method was used to determine the membrane fatty acid composition of $S$. thermophilus WT and heat-adapted strains [11]. The fatty acid compositions of $S$. thermophilus BIOPOP-1 and BIOPOP-2

Table 2. Comparison of relative fatty acid compositions between WT and Heat-Adapted strains by Streptococcus thermophilus BIOPOP-1 and BIOPOP-2.

\begin{tabular}{|c|c|c|c|c|}
\hline \multirow{2}{*}{ Fatty acid (FA) composition } & \multicolumn{2}{|c|}{ BIOPOP-1 } & \multicolumn{2}{|c|}{ BIOPOP-2 } \\
\hline & WT & Heat-Adapted & WT & Heat-Adapted \\
\hline C6:0 (\%) & $\mathrm{ND}^{\mathrm{a}}$ & $0.34 \pm 0.59$ & $\mathrm{ND}^{\mathrm{a}}$ & $0.35 \pm 0.61$ \\
\hline $\mathrm{C} 16: 0(\%)$ & $18.41 \pm 0.27$ & $14.36 \pm 0.16$ & $16.36 \pm 1.29$ & $22.78 \pm 1.28$ \\
\hline Sum of Short chain FA & $18.41 \pm 0.27$ & $14.70 \pm 0.96$ & $16.36 \pm 1.29$ & $23.13 \pm 1.61$ \\
\hline $\mathrm{C} 18: 0(\%)$ & $14.02 \pm 0.37$ & $13.89 \pm 0.06$ & $6.65 \pm 0.58$ & $9.28 \pm 0.77$ \\
\hline $\mathrm{C} 18: \ln 9 \mathrm{c}(\%)$ & $18.7 \pm 0.30$ & $14.99 \pm 0.55$ & $25.97 \pm 1.32$ & $21.61 \pm 0.29$ \\
\hline $\mathrm{C} 20: 0(\%)$ & $9.43 \pm 0.13$ & $13.54 \pm 0.23$ & $2.05 \pm 0.03$ & $1.96 \pm 0.11$ \\
\hline C20:1 (\%) & $36.9 \pm 0.49$ & $39.25 \pm 1.55$ & $47.25 \pm 2.68$ & $43.01 \pm 2.04$ \\
\hline C22:0 (\%) & $0.70 \pm 0.40$ & $1.19 \pm 0.4$ & $\mathrm{ND}^{\mathrm{a}}$ & $\mathrm{ND}^{\mathrm{a}}$ \\
\hline $\mathrm{C} 22: \ln 9(\%)$ & $2.31 \pm 0.09$ & $3.24 \pm 0.02$ & $1.71 \pm 0.45$ & $1.01 \pm 0.05$ \\
\hline Sum of Long chain FA & $81.59 \pm 0.16$ & $85.30 \pm 0.56$ & $83.64 \pm 0.74$ & $76.87 \pm 0.93$ \\
\hline Total & 100 & 100 & 100 & 100 \\
\hline SFA $^{\mathrm{b}}(\%)$ & $42.09 \pm 0.33$ & $42.52 \pm 2.14$ & $25.06 \pm 1.79$ & $34.37 \pm 3.11$ \\
\hline $\operatorname{UFA}^{c}(\%)$ & $57.91 \pm 0.19$ & $57.48 \pm 1.24$ & $74.94 \pm 1.03$ & $65.63 \pm 1.80$ \\
\hline UFA/SFA ratio & 1.38 & 1.35 & 2.99 & 1.91 \\
\hline
\end{tabular}

The viabilities are expressed as mean \pm standard deviation of the measurements of three biological replicates.

${ }^{a} \mathrm{ND}$ : Not Detected

bFA : Saturated Fatty Acid

${ }^{c}$ UFA : Unsaturated Fatty Acid 
strains are summarized details in Table 2. S. thermophilus BIOPOP-1 WT strain's membrane is made of seven fatty acids and that of heat-adapted strain consists of eight fatty acids. Also, in case of BIOPOP-2, membranes of WT and heat-adapted strains are composed of six and seven fatty acids correspondingly. The six common peaks in all strains were as follows; hexadecanoic (palmitic) acid (C16:0), octadecanoic (stearic) acid (C18:0), oleic acids (C18:1), arachidic (icosanoic) acid (C20:0), eicosenoic acid (C20:1), and erucic acids (C22:1) [25]. The results between the WT and heat-adapted strains were observed that the compositions of hexanoic acids (C6:0) and oleic acids (C18:1) were different. C18:1 composition of BIOPOP-1 and BIOPOP-2 heat-adapted strains were lower ( $14.99 \%$ and $21.61 \%$, respectively) than that of WT strains (18.7\% and $25.97 \%)$. Also, C6:0 was not detected in BIOPOP-1 and BIOPOP-2 WT strains, but heat-adapted strains were detected (BIOPOP-1: 0.34\%, BIOPOP-2: $0.35 \%)$. In addition, when comparing the BIOPOP-1 and BIOPOP-2 strains, only BIOPOP-1 strains was confirmed to have behenic (docosanoic) acid (C22:0): 0.34\% for WT strain and 1.19\% for heat-adapted strain.

The total fatty acid compositions were divided into two groups: saturated fatty acids (SFAs) and unsaturated fatty acids (UFAs) [23]. When we compared fatty acid composition of WT and heat-adapted strains, the total SFAs concentration of BIOPOP-1 heat-adapted strain was slightly higher that of WT strain, $42.09 \%$ and $42.52 \%$ correspondingly. In contrast, the total UFAs concentration decreased $57.91 \%$ for WT cells and $57.48 \%$ for heatadapted strain. In case of BIOPOP-2, the total SFAs concentration of heat-adapted strain was higher (34.37\%) than that of WT strain $(25.06 \%)$. On the contrary, the total UFAs concentration of heat-adapted was $65.63 \%$ and it was less than WT (74.94\%). As a result, both BIOPOP-1 and BIOPOP-2 featured increased ratios for saturated fatty acids, and reduced for unsaturated fatty acids. The UFA/SFA ratio are commonly used as indirect indicators of membrane fluidity [11]. The previous study was reported that high UFA/SFA ratio show a high membrane fluidity [35]. The UFA/SFA ratio of BIOPOP-1 and BIOPOP-2 observed for heat-adapted cells were lower (1.35 and 1.91, respectively) than WT (1.38 and 2.99, respectively). By analyzing these results, it can be observed with the decreased ratio between UFA/SFA, tolerance to various stresses increases [13].

\section{Discussion}

Heat tolerance is one of the most important abilities of LABs necessary to survive during manufacturing processes, such as food fermentation or pasteurization, in which they can be exposed to high temperatures (up to $60^{\circ} \mathrm{C}$ ) [5]. One study showed that heat tolerant Escherichia coli were developed by continuously cultivating the bacteria at $48.5^{\circ} \mathrm{C}$ [36]. In another study, researchers were able to increase the survival temperature of Corynebacterium glutamicum from $33^{\circ} \mathrm{C}$ to $41.5^{\circ} \mathrm{C}$ [37]. However, very few studies about manipulating tolerance of $S$. thermophilus strains through stress adaptation exist, and no studies have been done dedicated to manipulating the bacteria's heat tolerance in over $60^{\circ} \mathrm{C}$.

In this study, bacterial strains with elevated heat tolerance threshold were developed using heat adaptation method as shown Fig. 2. All experiments were carried out under sterile conditions and the risk of contamination during the experiments were eliminated. Several probiotic strains primarily isolated from fermented dairy foods in South Korea and two $S$. thermophilus of LAB that were able to survive at $50^{\circ} \mathrm{C}$ for $24 \mathrm{~h}$ were selected for this study. These two strains showed the difference that inherently high heat tolerance (BIOPOP-1) and those having low heat tolerance (BIOPOP-2) when cultured at $50^{\circ} \mathrm{C}$. The growth of strain BIOPOP- 1 was able to proliferate well $(97.59 \pm 1.40 \%)$, while BIOPOP-2 survived but hardly grew $(7.06 \pm 0.67 \%)$. This explains that strains of the same species can have different thresholds of heat tolerance. The adaptive evolution method was applied to the bacteria by gradually increasing the temperature and the final surviving bacteria were designated heat-adapted strains.

Fig. 3 shows that detectable changes in both strains started $72^{\circ} \mathrm{C}$ strains, and increased until achieving $84^{\circ} \mathrm{C}$ for BIOPOP-1, and $81^{\circ} \mathrm{C}$ for BIOPOP-2. Significant difference in the readings observed between start $\left(60^{\circ} \mathrm{C}\right)$ and each end (BIOPOP-1: $84^{\circ} \mathrm{C}$, BIOPOP-2: $81^{\circ} \mathrm{C}$ ) strains, suggesting that bacteria increased heat tolerance to a greater extent. It is theorized that the evolutionary shifts of both strains were triggered around temperature points over $70^{\circ} \mathrm{C}$

Two types of heat treatment experiments to compare viability between WT and heat-adapted strains conducted and the overall results matched with the hypothesis that the viabilities of heat-adapted strains were relatively higher than those of WT strains (Figs. 4 and 5). Also, WT strains were completely absent during the final stage of each experiment, whereas heat-adapted strain cells remained alive. In case of BIOPOP-1, general viability of heatadapted strain was higher than that of WT strain, but there was no significant difference in the values between WT and heat-adapted strain. However, in case of BIOPOP-2, the heat tolerance of heat-adapted strain increased substantially, and the results being significantly different compared to WT cells. In addition, an interesting observation was revealed that a strain with lower basal heat tolerance (BIOPOP-2) could extend its upper threshold by a greater value, while strain with higher basal heat tolerance (BIOPOP-1) would raise its upper limit to a very marginal extent. It might be considered that all bacteria have certain capacity to increase their stress tolerance limit. The lower the base values, the higher will the increment be, and higher based values mean there is less room for expansion.

Cross protection is based on mechanism that closely related responses are generated by different stress conditions [31]. In other words, different types of stresses lead to a common or similar type of response, as well as specific response by some stresses [17]. The strains in this study also expanded their cross-protection against multiple stress conditions such as high acidity, bile and salinity as a result of heat adaptation compared to WT strains. Probiotics must withstand multiple stress conditions to be able to colonize a colon of human in abundant numbers [38]. Before reaching the intestinal tract, probiotic bacteria must first survive acidic environment of the stomach generated by gastric juice [16]. In this experiment, heat-adapted strains exhibited higher level of acid tolerance than the control group. Upon reaching the intestine, probiotic bacteria face with another challenge, 
which is bile salts. It was confirmed that heat-adapted strains grew better than WT cells when they were exposed to $0.5 \%$ and $1 \%$ bile salts for $3 \mathrm{~h}$. Lactic acid bacteria can also be exposed to osmotic pressure during manufacture processes when additives such as salt or sugar are added to the product. Osmotic changes in the environment could rapidly damage essential cell functions, and bacteria need to adapt to such a change in order to survive [8]. They were exposed to $20 \% \mathrm{NaCl}$ for $2 \mathrm{~h}$ and $24 \mathrm{~h}$, and heat-adapted strain again demonstrated higher level of stress tolerance than WT cells. Overall, the bacteria became more tolerate to the above mentioned stress conditions they might face during manufacturing and ingestion processes.

The analysis of fatty acid contents was carried out to determine the cause of increased heat tolerance. The fatty acid composition and the ability of the cells to tolerant the above mentioned stresses are closely related. Heat adaptation to high temperatures can change the chain length of the membrane fatty acid, which can be raised with increasing temperature, and the short-chain composition of the membrane fatty acid increases [39]. However, in our study of $S$. thermophilus, chain length does not appear to be the main regulating mechanism that reacts to changes in the temperature regime (Table 2) [40]. Compared to BIOPOP-1 and BIOPOP-2, the heat-adapted strains increased their heat tolerance, but the BOPOP-1 heat-adapted strains decreased their short chain content and the BIOPOP-2 heat-adapted strains have increased. Therefore, there was no correlation between heat adaptation and overall chain length (short chain length vs. long chain length). Unlike chain lengths, the relative composition of fatty acids seems to play an important role of heat adaptation. Many researches have shown that lowering concentration of unsaturated fatty acids (UFAs) or increasing concentration of saturated fatty acids (SFAs) is decreased membrane fluidity and related to higher heat tolerance [11, 23, 34]. In our study, the modifications in $S$. thermophilus membrane fatty acid composition were clearly linked to its heat tolerance enhancement induced by constant heat shock to cells [25]. The membrane adaptation of S. thermophilus cells as a response to being exposed to high temperatures was clearly indicate a decrease in UFA/SFA ratio [41]. It suggests that composition of the cellular fatty acids plays an important role in the response to heat stress in these strains. The SFA enhances acyl-chain packing in the membrane, and thus increases van der Waal interactions between the chains, which consequently leads to decreased membrane fluidity [42]. And this raises its ability to withstand multiple stresses. The amount of SFAs capable of increasing acyl-chain packing in the cell membrane is considered to be one of the most important factors for successful growth under various stress environments [4]. Our results were similar to those previously described other bacteria such as Lactococcus lactis [4], Enterococcus faecium [23] and Pediococcus spp. [43].

BIOPOP-1 and BIOPOP-2 strain were equally affected to decrease in C18:1 content. These changes are characterized by organisms using anaerobic pathway of fatty acid biosynthesis, in which the majority of the decrease in unsaturated fatty acids in unsaturated fatty acids is in C18:1 [44]. Thus, like Avelino et al. reported [11], the modifications of the cell membrane composition in response to heat stress serve the purpose of maintaining a degree of fluidity compatible with life. Also, heat-adapted strains only showed hexanoic acid (C6:0) by the heat adaptation. We predicted that a related increase in C6:0 level probably due to the fact that a decrease of the oleic acid $(\mathrm{C} 18: 1)$ was induced to produce hexanoic acid (C6:0) during heat adaptation period [25]. We confirmed that the BIOPOP-1 strain is naturally more heat tolerant than BIOPOP-2. Fatty acid analysis revealed that the SFA contents of the BIOPOP-1 strain was higher than BIOPOP-2, and specifically, behenic (docosanoic) acid (C22:0) was identified only in the BIOPOP-1 strain. Through these results, we reaffirmed that the SFA contents affects the heat tolerance, and the higher the saturated fatty acid content, the higher the heat tolerance.

In this study, it was discovered that heat tolerant $S$. thermophilus strains can be obtained through heat adaptation procedure. Heat tolerance of heat-adapted strains was higher than that of WT strains and exhibited higher tolerance to other stress conditions like acid, bile salts and salinity. The physiological description of these stress tolerance enhancement after heat adaptation is provided by the membrane fatty acid composition observed for $S$. thermophilus cells. Heat-adapted strains showed UFA/SFA ratio inversely proportional to adaptation in constantly increasing heat temperatures. New SFA composition was observed and consequently the increase of SFA composition causes to decrease of membrane fluidity in the bacterial membrane. It could also explain the increase in D-values found for S. thermophilus in response to the increase in heat temperature. However, the changes observed in the membrane fatty acid composition are not enough to explain the influence of the various stress tolerance enhancement of $S$. thermophilus. Thus, further research is required to determine the exact molecular mechanisms for heat adaptation. This method proved to be useful in the dairy industry, and can definitely be utilized in various industries.

\section{Conflict of Interest}

The authors have no financial conflicts of interest to declare.

\section{References}

1. FAO/WHO. 2001. Health and nutritional properties of probiotics in food including powder milk with live lactic acid bacteria. Report of a Joint FAO/WHO Expert Consultation on Evaluation of Health and Nutritional Properties of Probiotics in Food Including Powder Milk with Live Lactic Acid Bacteria. Córdoba, Argentina: Food and Agricultural Organization of the United Nations, World Health Organization.

2. Lorenzo JM, Munekata P, Dominguez R, Pateiro M, Saraiva JA, Franco D. 2017. Main groups of microorganisms of relevance for food safety and stability: general aspects and overall description. Innov. Technol. Food Preserv. 2018: 53-107.

3. Cui Y, Xu T, Qu X, Hu T, Jiang X, Zhao C. 2016. New insights into various production characteristics of streptococcus thermophilus strains. Int. J. Mol. Sci. 17(10): 1701.

4. Chen J, Shen J, Ingvar Hellgren L, Jensen PR, Solem C. 2015. Adaptation of Lactococcus lactis to high growth temperature leads to a dramatic increase in acidification rate. Sci. Rep. 5: 14199. 
5. Angela L, Giuseppe S. 2019. Stress Responses of LAB. In Paramithiotis S, Patra JK, pp. 164-174 (Eds.), Food Mol. Microbiol. Boca Raton, U.S: CRC Press.

6. Torres-Maravilla E, Lenoir M, Mayorga-Reyes L, Allain T, Sokol H, Langella P, et al. 2016. Identification of novel anti-inflammatory probiotic strains isolated from pulque. Appl. Microbiol. Biotechnol.100: 385-396

7. Kishimoto T, Iijima L, Tatsumi M, Ono N, Oyake A, Hashimoto T, et al. 2010. Transition from positive to neutral in mutation fixation along with continuing rising fitness in thermal adaptive evolution. PLoS Genet. 6(10): e1001164.

8. Van de Guchte M, Serror P, Chervaux C, Smokvina T, Ehrlich SD, Maguin E. 2002. Stress responses in lactic acid bacteria. Antonie Van Leeuwenhoek 82: 187-216.

9. Guerzoni ME, Lanciotti R, Cocconcelli PS. 2001. Alteration in cellular fatty acid composition as a response to salt, acid, oxidative and thermal stresses in Lactobacillus helveticus. Microbiology 147: 2255-2264.

10. Ruiz L, Sánchez B, Ruas-Madiedo P, De Los Reyes-Gavilán CG, Margolles A. 2007. Cell envelope changes in Bifidobacterium animalis ssp. lactis as a response to bile. FEMS Microbiol. Lett. 274: 316-22.

11. Álvarez-Ordóñez A, Fernández A, López M, Arenas R, Bernardo A. 2008. Modifications in membrane fatty acid composition of Salmonella typhimurium in response to growth conditions and their effect on heat resistance. Int. J. Food Microbiol. 123:212-219.

12. Zhang YM, Rock CO. 2008. Membrane lipid homeostasis in bacteria. Nat. Rev. Microbiol 6: 222-233.

13. Beal C, Fonseca F, Corrieu G. 2010. Resistance to freezing and frozen storage of Streptococcus thermophilus is related to membrane fatty acid composition. J. Dairy Sci. 84: 2347-2356.

14. Auffray Y, Lecesne E, Hartke A, Boutibonnes P. 1995. Basic features of the Streptococcus thermophilus heat shock response. Curr. Microbiol. 30: 87-91.

15. Wei Y, Gao J, Liu D, Li Y, Liu W. 2019. Adaptational changes in physiological and transcriptional responses of Bifidobacterium longum involved in acid stress resistance after successive batch cultures. Microb. Cell Fact. 18(1): 156.

16. Guo L, Li T, Tang Y, Yang L, Huo G. 2016. Probiotic properties of enterococcus strains isolated from traditional naturally fermented cream in China. Microb. Biotechnol. 9: 737-745.

17. Kim WS, Perl L, Park JH, Tandianus JE, Dunn NW. 2001. Assessment of stress response of the probiotic Lactobacillus acidophilus. Curr. Microbiol. 43: 346-350.

18. Devereux R, Willis SG. 2011. Amplification of ribosomal RNA sequences. In Mol. Microb. Ecol. Man. pp. 277-287.

19. Kim O-S, Cho Y-J, Lee K, Yoon S-H, Kim M, Na H, et al. 2012. Introducing EzTaxon-e: a prokaryotic 16S rRNA gene sequence database with phylotypes that represent uncultured species. Int. J. Syst. Evol. Microbiol. 62: 716-721.

20. Kumar S, Stecher G, Li M, Knyaz C, Tamura K. 2018. MEGA X: Molecular evolutionary genetics analysis across computing platforms. Mol. Biol. Evol. 35: 1547-1549.

21. Barrick JE, Yu DS, Yoon SH, Jeong H, Oh K, Schneider, et al. 2009. Genome evolution and adaptation in a long-term experiment with Escherichia coli. Nature 461: 1243-1247.

22. Shibai A, Takahashi Y, Ishizawa Y, Motooka D, Nakamura S, Ying BW, et al. 2017. Mutation accumulation under UV radiation in Escherichia coli. Sci. Rep. 7(1): 14531.

23. Shin YJ, Kang CH, Kim W, So JS. 2018. Heat Adaptation improved cell viability of probiotic Enterococcus faecium HL7 upon various environmental stresses. Probiotics Antimicrob. Proteins 11: 618-626.

24. Mazzola PG, Penna TCV, da S Martins AM. 2003. Determination of decimal reduction time (D value) of chemical agents used in hospitals for disinfection purposes. BMC Infect. Dis. 3: 24

25. Álvarez-Ordóñez A, Fernández A, López M, Bernardo A. 2009. Relationship between membrane fatty acid composition and heat resistance of acid and cold stressed Salmonella senftenberg CECT 4384. Food Microbiol.

26. Lee KW, Shim JM, Park SK, Heo HJ, Kim HJ, Ham KS, et al. 2016. Isolation of lactic acid bacteria with probiotic potentials from kimchi, traditional Korean fermented vegetable. LWT - Food Sci. Technol. 26: 347-353.

27. GarcÉs R, Mancha M. 1993. One-step lipid extraction and fatty acid methyl esters preparation from fresh plant tissues. Anal. Biochem. 211: 139-143.

28. R Development Core Team R. 2011. R: A Language and Environment for Statistical Computing. R Found. Stat. Comput.

29. Ghattargi VC, Nimonkar YS, Burse SA, Davray D, Kumbhare SV, Shetty SA, et al. 2018. Genomic and physiological analyses of an indigenous strain, Enterococcus faecium 17OM39. Funct. Integr. Genomics.

30. Caspeta L, Chen Y, Nielsen J. 2016. Thermotolerant yeasts selected by adaptive evolution express heat stress response at $30^{\circ} \mathrm{C}$. Sci. Rep. 6: 27003

31. Wang C, Cui Y, Qu X. 2018. Mechanisms and improvement of acid resistance in lactic acid bacteria. Arch. Microbiol. 200: 195-201.

32. Álvarez-Ordóñez A, Begley M, Prieto M, Messens W, López M, Bernardo A, et al. 2011. Salmonella spp. survival strategies within the host gastrointestinal tract. Microbiology 157: 3268-3281.

33. Maragkoudakis PA, Zoumpopoulou G, Miaris C, Kalantzopoulos G, Pot B, Tsakalidou E. 2006. Probiotic potential of Lactobacillus strains isolated from dairy products. Int. Dairy J. 16: 188-199.

34. Abee T, Wouters JA. 1999. Microbial stress response in minimal processing. Int. J. Food Microbiol. 50: 65-91.

35. Casadei MA, Mañas P, Niven G, Needs E, Mackey BM. 2002. Role of membrane fluidity in pressure resistance of Escherichia coli NCTC 8164. Appl. Environ. Microbiol. 68: 5965-5972.

36. Rudolph B, Gebendorfer KM, Buchner J, Winter J. 2010. Evolution of Escherichia coli for growth at high temperatures. J. Biol. Chem. 285: $19029-19034$.

37. Oide S, Gunji W, Moteki Y, Yamamoto S, Suda M, Jojima T, et al. 2015. Thermal and solvent stress cross-tolerance conferred to Corynebacterium glutamicum by adaptive laboratory evolution. Appl. Environ. Microbiol. 81: 2284-2298.

38. Henriksson A, Khaled AKD, Conway PL. 1999. Lactobacillus colonization of the gastrointestinal tract of mice after removal of the non-secreting stomach region. Microb. Ecol. Health Dis. 11: 96-99.

39. Suutari M, Laakso S. 1994. Microbial fatty acids and thermal adaptation. Crit. Rev. Microbiol. 20: 285-328.

40. Bajerski F, Wagner D, Mangelsdorf K. 2017. Cell membrane fatty acid composition of Chryseobacterium frigidisoli PB4T, isolated from antarctic glacier forefield soils, in response to changing temperature and pH conditions. Front. Microbiol. 8: 677.

41. Wang Y, Corrieu G, Béal C. 2005. Fermentation pH and temperature influence the cryotolerance of Lactobacillus acidophilus RD758. J. Dairy Sci. 88: 21-29.

42. Fulco AJ. 1983. Fatty acid metabolism in bacteria. Prog. Lipid Res. 22: 133-160.

43. Annous BA, Kozempel MF, Kurantz M J. 1999. Changes in membrane fatty acid composition of Pediococcus sp. strain NRRL B-2354 in response to growth conditions and its effect on thermal resistance. Appl. Environ. Microbiol. 65: 2857-2862.

44. Russell NJ, Evans RI, ter Steeg PF, Hellemons J, Verheul A, Abee T. 1995. Membranes as a target for stress adaptation. Int. J. Food Microbiol. 28: 255-261. 